\title{
Schools Have Contextual Influence on Smoking Behavior among High School Students in Dumai, Riau
}

\author{
Shilfia Ulfa Islami'), Hanung Prasetya ${ }^{2)}$ \\ Bhisma Murti3) \\ 1)Masters Program of Public Health, Universitas Sebelas Maret \\ ${ }^{2}$ School of Health Polytechnic, Ministry of Health, Surakarta
}

\begin{abstract}
Background: Adolescence is prone to smoking behavior. Smoking behavior in adolescents is influenced by parental income factors, pocket money, media exposure, peers, the influence of parents, and attitudes towards smoking behavior. The purpose of this study was to analyze the contextual influence of school on smoking behavior in adolescents in Dumai City, Riau.

Subject and Method: This was a cross sectional study conducted at 13 senior high schools and 12 junior high schools in Dumai, Riau, Indoneisa, from September to October 2019. A sample of 200 male adolescents aged 12-18 years was selected by stratified random sampling. The dependent variable was smoking behavior. The independent variables were parental income, pocket money, media exposure, peer, parental influence, intention, attitude, subjective norm, and perceived behavior control (PBC). The data were collected by questionnaire and analyzed by a multilevel multiple logistic regression run on Stata 13.

Results: Smoking behavior in male adolescents increased with high parental income $(b=2.06$; $95 \% \mathrm{CI}=-0.02$ to $4.15 ; \mathrm{p}=0.053)$, high pocket money $(\mathrm{b}=2.75 ; 95 \% \mathrm{CI}=0.80$ to $4.71 ; \mathrm{p}=0.006)$, high exposure to cigarette advertising media $(b=2.45 ; 95 \% \mathrm{CI}=0.52$ to $4.37 ; \mathrm{p}=0.012)$, peer $(b=2.10 ; 95 \% \mathrm{CI}=0.46$ to $3.74 ; \mathrm{p}=0.012)$, parental smoking behavior $(\mathrm{b}=2.23 ; 95 \% \mathrm{CI}=0.47$ to 3.99; $\mathrm{p}=0.013)$, and positive attitude to smoke $(\mathrm{b}=2.67 ; 95 \% \mathrm{CI}=0.78$ to $4.55 ; \mathrm{p}=0.005)$. Smoking behavior decreased with weak PBC $(\mathrm{b}=-2.33$; 95\% $\mathrm{CI}=-405$ to $-0.60 ; \mathrm{p}=0.008)$, weak intention $(b=-3.85 ; 95 \% C I=-6.32$ to $-1.39 ; p=0.002)$, and weak subjective norm $(b=-3.03 ; 95 \% \mathrm{CI}=-5.16$ to 5.16; $\mathrm{p}=0.005$ ). There was strong contextual effect of school on smoking behavior in male adolescents with intra-class (ICC) $=25.14 \%$.

Conclusions: Smoking behavior in male adolescents increases with high parental income, high pocket money, high exposure to cigarette advertising media, peer, parental smoking behavior, and positive attitude to smoke. Smoking behavior decreases with weak PBC, weak intention, and weak subjective norm. There is strong contextual effect of school on smoking behavior in male adolescents.
\end{abstract}

Keywords: smoking behavior, adolescents, school

\section{Correspondence:}

Shilfia Ulfa Islami. Masters Program in Public Health, Universitas Sebelas Maret. Jl. Ir. Sutami 36A, Surakarta 57126, Central Java, Indonesia. Email: shilfiaulfa17@gmail.com. Mobile: 085219722029.

\section{BACKGROUND}

Adolescence is a transition period with changes in physical, cognitive, personal, and social status. Adolescence is very significant in terms of changes in the development of health-related behaviors due to periods of searching for identity. WHO
(2015) reports from the 2014 Tobacco Global Youth Survey (GYTS) in Indonesia that $20.3 \%$ of adolescents aged 13-15 smoke tobacco products. Adolescents have the highest risk of smoking initiation and have the potential to become adult smokers in the future (Bigwanto et al., 2015). 
Journal of Health Promotion and Behavior (2019), 4(3): 212-223

https://doi.org/10.26911/thejhpb.2019.04.03.06

Basic Health Research Data (2018) showed that the proportion of tobacco consumption (suction and chewing) in the population aged $\geq 15$ years old who smoked in 2013 was $36.3 \%$, in 2016 there was a decrease to $32.8 \%$, but in 2018 the proportion of tobacco consumption increased to $33.8 \%$. Basic health research data reported the prevalence of smoking in the population aged 10-18 years old there was an increase from 2013 to 2018 where in 2013 was $7.2 \%$, in 2016 it was $8.8 \%$ and in 2018 was $9.1 \%$.

Factors that influence the initiation of smoking in adolescents according to Bacopoulou et al. (2018) are peers, educational institutions, places of entertainment, and family. The research of Bobo et al. (2018) states that other factors are pocket money, fathers who smoke, perceptions that boys who smoke are more attractive and cooler. In contrary, the study of Xu et al. (2016) mentioned that students' motivation to smoke for the first time was curiosity, relieving stress/social pressure, and imitating smoker friends. The pattern of smoking behavior carried out during adolescence tends to last into adulthood (Cole et al., 2019). To reduce the high consumption of cigarettes among teenagers, it is necessary to have policies that are implemented such as the No Smoking Area in schools.

Indonesia already has a No Smoking Area (NSA) regulation to prevent the high number of smokers, namely the existence of Regulation of the Minister of Health and the Minister of Home Affairs Number 188/Minister of Health/Pb/I/2011 and No.7 of 2011 concerning Guidelines for the Development of No Smoking Areas (NSA) which mentions the need for the implementation of NSA in health service facilities, places for teaching and learning processes, where children play, places of worship, public transportation, workplace, and other public places (Minister of Health RI, 2011).
Schools are educational institutions that have influence in forming attitudes. Schools without cigarettes can alert students to the dangers of tobacco as early as possible and can also learn risky behavior among students (Bendaou et al., 2018).

\section{SUBJECTS AND METHOD \\ 1. Study Design \\ This was an analytic observational study with a cross sectional design. The study was conducted at 13 Senior high schools and 12 Junior high schools in Dumai, Riau, Indo- nesia, from September to October 2019.}

\section{Population and Sample}

The study population were all male adolescents. A sample of 200 male adolescents was selected by stratified random sampling.

\section{Study Variables}

The dependent variable was smoking behavior. The independent variables were intention, attitude, subjective norm, and perceived behavior control, parental income, pocket money, media exposure, peer, and parental influence.

\section{Operational Definition of Variables}

Parents income measured based on the results of income received monthly for the last 6 months by parents in fulfilling their daily needs. The data were collected by questionnaire. The measurement scale was continous and transformed into dichotomous, coded o for $<$ Rp 2,80o,00o and 1 for $\geq$ Rp 2,800,o00.

Pocket money was money given by parents or other families to fulfill the needs of adolescents. The data were collected by questionnaire. The measurement scale was continous and transformed into dichotomous, coded o for $<$ Rp 10,00o and 1 for $\geq R p$ 10,000 .

Media exposure was adolescent exposure through various mass media, electronic media related to cigarette advertisements/ promotions, whether they are read, heard 
or seen. The data were collected by questionnaire. The measurement scale was continous and transformed into dichotomous, coded $\mathrm{o}$ for $<$ mean and 1 for $\geq$ mean.

Peer was adolescents with the same level of age as well as involving a relatively large familiarity between groups. The data were collected by questionnaire. The measurement scale was continous and transformed into dichotomous, coded o for $<$ mean; $1=\geq$ mean.

Parents influence was a relationship between two or more individuals joined together because of a blood relationship where there are feelings of mutual trust, close, open, bound, interconnected and sharing. The data were collected by questionnaire. The measurement scale was continous and transformed into dichotomous, coded o for low and 1 for high.

Intention was the desire of adolescents to choose whether they participate in smoking behavior or not. The data were collected by questionnaire. The measurement scale was continous and transformed into dichotomous, coded o for weak and 1 for strong.

Attitude was the response of adolescents in the form of a positive or negative assessment related to the ease or obstacles affecting adolescents in smoking behavior. The data were collected by questionnaire. The measurement scale was continous and transformed into dichotomous, coded o for negative and 1 for positive.

Subjective Norm was a belief about the support felt by adolescents from the social environment, family, and peers who have an influence on adolescent decisions in smoking behavior. The data were collected by questionnaire. The measurement scale was continous and transformed into dichotomous, coded o for weak and 1 for low.

Perceived behavioral control was an adolescents' perception related to smoking behavior. The data were collected by questionnaire. The measurement scale was continous and transformed into dichotomous, coded o for weak and 1 for strong.

Smoking behavior was smoking behavior or habit in adolescents. The data were collected by questionnaire. The measurement scale was continous and transformed into dichotomous, coded o for not smoking and 1 for smoking

\section{Data Analysis}

Univariate analysis was run to describe each variable. Bivariate analysis used to examine the effects of intention, attitude, subjective norm, perceived behavior control, parental income, pocket money, media exposure, peer, parental influence, and smoking behavior in adolescents.

Multilevel analysis was used to examine the influence of intention, attitude, subjective norm, perceived behavioral control, parental income, pocket money, media exposure, peer, and parental influence on smoking behavior in the first level. The variable at the second level was schools.

\section{Research Ethics}

This study was conducted based on informed consent, anonymity, confidentiality, and ethical research. Research ethics was obtained from the Research Ethics Committee at Dr. Moewardi Hospital, Surakarta, Central Java, Indonesia, with No. 1.012/VIII/HREC/2019.

\begin{tabular}{l}
\hline RESULTS \\
1. Sample Characteristics \\
The categorical data sample description \\
described the continuous data of each study \\
variable including pocket money, media \\
exposure, peers, parental influence, inten- \\
tion, attitude, subjective norm, and per- \\
ceived of behavior control. The results of \\
the analysis of the description of categorical \\
data samples were shown in the Table 1 .
\end{tabular}


Journal of Health Promotion and Behavior (2019), 4(3): 212-223

https://doi.org/10.26911/thejhpb.2019.04.03.06

Table 1. Sample characteristics of continous data

\begin{tabular}{lccccc}
\hline \multicolumn{1}{c}{ Variables } & N & Mean & SD & Min. & Max. \\
\hline Pocket Money & 200 & 10,000 & 5.36 & 20,00 & 50,000 \\
Media Exposure & 200 & 7.29 & 2.08 & 2 & 10 \\
Peer & 200 & 7.75 & 3.34 & 2 & 17 \\
Parental Influence & 200 & 7.54 & 2.22 & 2 & 16 \\
Intention & 200 & 5.05 & 2.57 & 2 & 12 \\
Attitude & 200 & 17.7 & 2.35 & 6 & 20 \\
Subjectuve Norm & 200 & 9.04 & 2.99 & 2 & 16 \\
Perceived Behavioral Control & 200 & 8.81 & 2.89 & 1 & 12 \\
\hline
\end{tabular}

2. Univariate Analysis

Table 2. Sample characteristics of categorical data

\begin{tabular}{lcc}
\multicolumn{1}{c}{ Variables } & Score & (\%) \\
\hline Parent's Income & 68 & \\
Low (<Rp 2,800,000) & 132 & 34.0 \\
High ( $\geq$ Rp 2,800,000) & 71 & 66.0 \\
Pocket Money & 129 & 35.5 \\
Low (<Rp 10,000) & 61 & 64.5 \\
High ( $\geq$ Rp 10,000) & 139 & 30.5 \\
Media Exposure & & 69.5 \\
Low (score <7) & 96 & 48.0 \\
High (score $\geq 7$ ) & 104 & 52.0 \\
Peer & & \\
Not smoking (score <8) & 69 & 34.5 \\
Smoking (score $\geq 8)$ & 131 & 65.5 \\
Parental influence & & \\
Weak (score $<7$ ) & 107 & 53.5 \\
Strong (score $\geq 7$ ) & 93 & 46.5 \\
Intention & & 46.5 \\
Weak (score $<5$ ) & 93 & 53.6 \\
Strong (score $\geq 5$ ) & 107 & \\
Attitude & & 54.0 \\
Negative (score <18) & 108 & 46.0 \\
Positive (score $\geq 18)$ & 92 & 46.5 \\
Subjective Norm & & 53.5 \\
Weak (score <9) & 93 & 37.5 \\
Weak (score $\geq 9$ ) & 107 & 62.5 \\
Perceived Behavioral Control & & \\
Strong (score <9) & 75 & \\
Weak (score $\geq 9$ ) & 125 & \\
Smoking Behavior & & \\
Not Smoking & & \\
Smoking & & \\
\hline
\end{tabular}

Table 2 showed that $66 \%$ adolescents had high-income parents $\geq \mathrm{Rp} 2,800,000$, $64.5 \%$ adolescents had high pocket money $\geq$ Rp 10,000, 69.5\% exposed to cigarette media exposure, and $46.5 \%$ had strong intention to smoke. Half of $53.6 \%$ male adolescents had positive attitude to smoke, weak subjective norm (54\%), and weak perceived behaviour control (53.55\%). 
Islami et al./ Schools have contextual influence on smoking behavior

3. Bivariate Analysis

Table 3. Chi-square test of factors influencing smoking behavior in male adolescents

\begin{tabular}{|c|c|c|c|c|c|c|c|c|}
\hline \multirow{3}{*}{$\begin{array}{c}\text { Independent } \\
\text { variables }\end{array}$} & \multicolumn{4}{|c|}{ Smoking Status } & \multirow{2}{*}{\multicolumn{2}{|c|}{ Total }} & \multirow{3}{*}{$\mathbf{O R}$} & \multirow{3}{*}{$\mathbf{p}$} \\
\hline & \multicolumn{2}{|c|}{ Not Smoking } & \multicolumn{2}{|c|}{ Smoking } & & & & \\
\hline & $\mathbf{n}$ & $\%$ & $\mathbf{n}$ & $\%$ & $\mathbf{n}$ & $\%$ & & \\
\hline \multicolumn{9}{|l|}{ Parental Income } \\
\hline Low $(<\operatorname{Rp} 2,800,000)$ & 43 & 63.2 & 25 & 36.7 & 68 & 100 & $5 \cdot 37$ & $<0.001$ \\
\hline High ( $\geq$ Rp 2,800,000) & 32 & 24.2 & 100 & $75 \cdot 7$ & 132 & 100 & & \\
\hline \multicolumn{9}{|l|}{ Pocket Money } \\
\hline Low (< Rp. 10,000) & 49 & 69.1 & 22 & 30.9 & 71 & 100 & 8.82 & $<0.001$ \\
\hline High ( $\geq$ Rp. 10,000 $)$ & 26 & 20.1 & 103 & 79.8 & 129 & 100 & & \\
\hline \multicolumn{9}{|l|}{ Media Exposure } \\
\hline Low $($ score $<7)$ & 16 & 26.2 & 45 & 73.7 & 61 & 100 & 0.48 & 0.029 \\
\hline High (score $\geq 7$ ) & 59 & 42.4 & 80 & 57.5 & 139 & 100 & & \\
\hline \multicolumn{9}{|l|}{ Peer } \\
\hline Not smoking (score $<8$ ) & 61 & 63.5 & 35 & 36.4 & 96 & 100 & 11.2 & $<0.001$ \\
\hline Smoking (score $\geq 8$ ) & 14 & 13.4 & 90 & 86.5 & 104 & 100 & & \\
\hline \multicolumn{9}{|l|}{ Parental influence } \\
\hline Weak (score <7) & 47 & 68.1 & 22 & 31.8 & 69 & 100 & 7.85 & $<0.001$ \\
\hline Strong (score $\geq 7$ ) & 28 & 21.3 & 103 & 78.6 & 131 & 100 & & \\
\hline \multicolumn{9}{|l|}{ Intention } \\
\hline Weak (score <5) & 70 & 65.4 & 37 & 34.5 & 107 & 100 & 33.2 & $<0.001$ \\
\hline Strong (score $\geq 5$ ) & 5 & $5 \cdot 38$ & 88 & 94.6 & 93 & 100 & & \\
\hline \multicolumn{9}{|l|}{ Attitude } \\
\hline Negative (score $<18$ ) & 45 & 48.3 & 48 & 51.6 & 93 & 100 & 2.40 & 0.003 \\
\hline Positive (score $\geq 18$ ) & 30 & 28.0 & 77 & 71.9 & 107 & 100 & & \\
\hline \multicolumn{9}{|l|}{ Subjective Norm } \\
\hline Weak (score <9) & 65 & 60.1 & 43 & 39.8 & 108 & 100 & 12.3 & $<0.001$ \\
\hline Strong (score $\geq 9$ ) & 10 & 10.8 & 82 & 89.1 & 92 & 100 & & \\
\hline \multicolumn{9}{|l|}{ PBC } \\
\hline Strong (score <9) & 14 & 15.0 & 79 & 84.9 & 93 & 100 & 0.13 & $<0.001$ \\
\hline Weak (score $\geq 9$ ) & 61 & 37.5 & 46 & 42.9 & 107 & 100 & & \\
\hline
\end{tabular}

Table 3 showed that parental income $(\mathrm{OR}=$ 5.37; $\mathrm{p}<0.001)$, pocket money $(\mathrm{OR}=8.82$; $\mathrm{p}<0.001)$, media exposure $(\mathrm{OR}=0.48 ; \mathrm{p}=$ 0.029), peer $(\mathrm{OR}=11.2 ; \mathrm{p}<0.001)$, parent's influence $(\mathrm{OR}=7.85 ; \mathrm{p}<0.001)$, intention $(\mathrm{OR}=33.2 ; \mathrm{p}<0.001)$, attitude $(\mathrm{OR}=2.40$; $\mathrm{p}=0.003)$, subjective norm $(\mathrm{OR}=12.3 ; \mathrm{p}$ $<0.001$ ), and perceived behavioral control $(\mathrm{OR}=0.13 ; \mathrm{p}<0.001)$

\section{Multilevel Analysis}

Multilevel analysis was using multilevel multiple logistic regression methods and analyzed by using Stata 13. Table 4 showed the influence of intention, attitude, subjective norm, perceived behavioral control, parental income, pocket money, media exposure, peer, parental influence on smoking behavior in male adolescents. High parental income $(b=2.06 ; 95 \% \mathrm{CI}=-0.02$ to 4.15 ; $\mathrm{p}=0.053)$, high pocket money $(\mathrm{b}=2.75$; 95\% CI $=0.80$ to $4.71 ; \mathrm{p}=0.006$ ), high exposure to cigarette advertising media $(b=2.45$; 95\% CI $=0.52$ to $4.37 ; \mathrm{p}=0.012)$, peer $(\mathrm{b}=$ 2.10; $95 \% \mathrm{CI}=0.46$ to $3.74 ; \mathrm{p}=0.012)$, parental influence $(b=2.23 ; 95 \% \mathrm{CI}=0.47$ to 3.99; $\mathrm{p}=0.013)$, and positive attitude $(\mathrm{b}=$ 2.67; 95\% $\mathrm{CI}=0.78$ to $4.55 ; \mathrm{p}=0.005$ ) increased smoking behavior in male adolescents. Weak perceived behavior control $(b=$ -2.33; 95\% CI= -405 to $-0.60 ; \mathrm{p}=0.008)$, weak intention $(b=-3.85 ; 95 \% \mathrm{CI}=-6.32$ to -1.39; $p=0.002$ ), and weak subjective norm $(b=-3.03 ; 95 \% \mathrm{CI}=-5.16$ to $5.16 ; \mathrm{p}=0.005)$ decreased smoking behavior in male ado- 
Journal of Health Promotion and Behavior (2019), 4(3): 212-223

https://doi.org/10.26911/thejhpb.2019.04.03.06

lescents. Schools had contextual effect on smoking behavior among male adolescents with intra-class correlation $($ ICC $)=25.14 \%$.

It means that variations in smoking behavior in adolescents were $25.14 \%$ determined at the school level.

Table 4. Multilevel multiple logistic regression analysis of smoking behavior in adolescents

\begin{tabular}{|c|c|c|c|c|}
\hline \multirow[b]{2}{*}{ Independent Variables } & \multirow{2}{*}{ b } & \multicolumn{2}{|c|}{$95 \%$ CI } & \multirow[b]{2}{*}{ p } \\
\hline & & Lower Limit & Upper Limit & \\
\hline \multicolumn{5}{|l|}{ Fixed Effect } \\
\hline Parents Income (>Rp.2,800,000) & 2.06 & -0.02 & 4.15 & 0.053 \\
\hline Pocket Money (>Rp.10,ooo) & 2.75 & 0.80 & 4.71 & 0.006 \\
\hline Media Exposure (High) & 2.45 & 0.52 & $4 \cdot 37$ & 0.012 \\
\hline Majority of Peer (Smoking) & 2.10 & 0.46 & 3.74 & 0.012 \\
\hline Parental Influence to Smoke (Strong) & 2.23 & 0.47 & 3.99 & 0.013 \\
\hline Smoking Intention (Weak) & -3.85 & -6.32 & -1.39 & 0.002 \\
\hline Smoking Behavior (Positive) & 2.67 & 0.78 & 4.55 & 0.005 \\
\hline Subjective Norm (Weak) & -3.03 & -5.16 & -0.90 & 0.005 \\
\hline Perceived behavioral Control (Weak) & -2.33 & -4.05 & -4.05 & 0.008 \\
\hline \multicolumn{5}{|l|}{ Random Effect } \\
\hline \multicolumn{5}{|l|}{ School } \\
\hline Variation (constants) & 1.10 & 0.06 & 18.5 & \\
\hline n observation $=200$ & & & & \\
\hline Log Likelihood= -33.45 & & & & \\
\hline LR test vs. logistic regression, $p=0.139$ & & & & \\
\hline Intra-class Correlation (ICC) $=25.14 \%$ & & & & \\
\hline
\end{tabular}

\section{DISCUSSIONS}

\section{The effect of family income on smoking behavior}

Parental income has a significant influence on smoking behavior in adolescents. High parental income $\geq$ Rp. 2,800,00o affected smoking behavior by 2.06 units higher than adolescents who had lower parental income. High parental income made it possible to provide an allowance or greater adolescents' needs, which allowed adolescents to make decisions and purchases without a financial barrier. Purnaningrum et al. (2017), stated that all income received by a person whether it came from direct involvement in the production process or not, which can be measured in money and used to fulfill needs. Parents' income and occupation would certainly be related to their level of education (Rattay et al., 2018).

The low level of education affected the income they earn, so it was not surprising that the prevalence of smoking behavior in children of parents with low employment rates was higher when compared to the prevalence of smoking behavior in children of parents with high employment rates.

2. The effect of pocket money on smoking behavior

Pocket money has a significant influence on smoking behavior in adolescents. Adolescents with high allowances >IDR 10,000 behave smoking 2.75 higher than adolescents who have low allowances. The allowance included an independent and consistent predictor of smoking among adolescents because this determined actions to buy cigarettes, the level of addiction, and the intensity of smoking. Adolescents who have more allowance would produce a slightly higher probability of smoking initiation (Cui et al., 2019)

Management of pocket money owned by adolescents was used for personal gain and also to buy cigarettes, most of the subjects used their allowance buy retail 
cigarettes on a daily basis at the stall. Parents provide pocket money to fulfill their needs in school. The findings showed that some adolescents use an allowance given by parents per day used to buy cigarettes. Moor et al. (2019) stated that an allowance provided resources to buy tobacco. Giving too much allowance and not supervised by parents made adolescents buy their needs or buy cigarettes with easy access.

\section{The effect of media exposure on smoking behavior}

Media exposure has a significant effect on smoking behavior in adolescents. Adolescents who were exposed to cigarette advertising media have 2.45 units higher than those who were rarely exposed to cigarette advertising media. Increased media consumption can help consumers shape the perception of reality. Social media can function as an effective channel for adolescents to know things easily. Exposure to cigarette advertisements was also intended to give adolescents the intention to smoke indirectly increasing their idea that smoking was something that causes adolescents to have a tendency to smoke (Pandayu et al., 2017).

Media exposure was positively related to adolescent's vulnerability to smoking behavior in the future (Sudo and Kuroda, 2017). The media was also a strong factor in determining social norms for adolescents (Alsayyari and Albuhairan, 2018). Adolescents were very vulnerable to messages and images conveyed through various media. The promotion of cigarette advertisements was using banners, magazines, TV, internet, etc. gave a positive connotation so that it indirectly increased adolescents' belief that smoking is cool, interesting, fun and is a trend among adolescents to smoke (Soesyasmoro et al., 2017).

\section{The effect of peer on smoking beha- vior among adolescents}

Peers have a positive influence on smoking behavior in adolescents. Adolescents who have smoker friends have 2.10 units higher than adolescents who have non-smoking friends. Adolescents spent many of their days interacting with peers. In adolescence, peer sensitivity would increase compared to other periods of life (Bruine et al., 2019). The need to be accepted among peers made them willing to do anything including smoking (Pandayu et al., 2017). Research done by Moor et al. (2019) showed that adolescents chose friends based on similar behavior during the formation of friendships.

The effect of high conformity occurred because adolescents have free time to gather with peers rather than family so that attitudes, conversations, appearances to be influenced by peers. Research done by Er et al. (2019) showed that the role of peers increased smoking behavior because of having friends outside of school. The findings found that the influence of friends outside of school has a great influence on adolescent smoking behavior.

Self-confidence in adolescence often made them indecisive in taking actions and decisions. The lack of trust felt by adolescents made them looked for groups that they think can make themselves safe. Adolescents started smoking behavior by paying attention to the socio-cultural environment (Wu et al., 2019).

\section{The effect of parental influence on smoking behavior}

The influence of parents has a significant effect on smoking behavior in adolescents. The influence of parents who smoke for smoking behavior was 2.23 units more powerful than the adolescents who have parents (fathers) who did not smoke. The family environment of smokers or fathers 
who smoke played a role in the initiation, use and perseverance of adolescents to smoke (Steeger et al., 2019). Parental involvement was related to communication. A low level of parental communication correlated positively with smoking when adolescents felt that they were not so close to parents that they were seen as rebelling against parents (Aho et al., 2017).

Previous researchers found that intergenerational transmission, which influenced factors due to the lack of rules at home related to cigarettes (Vitória et al., 2020), lack of discussion of the dangers of smoking (Mak, 2018), and lack of parental supervision of children. Parents who smoke also have difficulty in keeping their children from smoking. Cognitive theory by Bandura (1986) stated that parental control may not only be directly related to smoking.

\section{The effect of intention on smoking behavior among adolescents}

Intention has a significant effect on smoking behavior in adolescents. Adolescents with weak intentions have 3.85 units lower than those who have strong intentions towards cigarettes. The intention to smoke in adolescents was caused by several external factors, namely the presence of friends or family who smoke. These findings were supported by theory of planned behavior (TPB) which stated that behavior was determined by the behavioral control and intention to become a behavior. Intentions were influenced by attitudes, subjective norms, and behavior control of individuals, these three components interacted with each other and became determinants of the formation of an intention that was done or not done (Cousson-gélie et al., 2018).

Cognitive and psychological involvement with schools and having peers who smoke were associated with high smoking intentions ( $\mathrm{Ra}$ and Jung, 2018). Adoles- cents tend to share attitudes, beliefs and norms of behavior with peers to gain trust. The smoking behavior of peers can be strongly associated with higher levels of adolescent's intention to smoke. Social norms were a strong determinant of smoking intentions.

\section{The effect of attitude on smoking behavior among adolescents}

Attitude has a significant influence on smoking behavior in adolescents. Adolescents who have positive attitudes towards smoking behavior were 2.67 units higher than those who have negative attitudes. Curiosity about cigarettes was one of the biggest influence for adolescents to start smoking (Nurmansyah et al., 2019). A positive attitude towards the initiation of smoking and has been related to motivation to smoke (Aura et al., 2016)

Attitudes were formed from peers, parents and the media. Peers and parents have been shown to have the strongest influence on smoking. Adolescents who smoke think that smoking can reduce stress levels. In addition, adolescents who smoke were also more likely to agree that smoking increases trust, made a person look cooler and symbolized maturity (masculinity). Adolescents who smoke stated that smoking made it easier for them to make friends (Bruine et al., 2019).

Attitude is a personal assessment that supports the theory of planned behavior (TPB) which showed that behavior was formed due to the influence of strong intentions and in a person and was determined by one of the concepts namely attitude (Colombo et al., 2019)

\section{The effect of subjective norm on smoking behavior}

Subjective norms have a significant influence on smoking behavior. Adolescents who have weak subjective norms on smoking behavior were 3.03 units lower 
than adolescents who have strong subjective norms on smoking behavior. Subjective norms explained the extent to which a person has the motivation to follow people's views of the behavior he/she did (normative belief) (Sulaeman, 2016). The findings showed that adolescents who have weak subjective norms have a better influence to avoid smoking behavior compared to adolescents who have strong subjective norms. This was explained that the existence of a supportive social environment around adolescents helped the adolescents to have smoking behavior.

Norms have an important role as a social controller (social control) as well as social order (social order) by applying social pressure to individuals who obey it. This supported the theory of planned behavior which stated that behavior was formed by the influence of strong intentions in individuals that were determined by subjective norms (Sulaeman, 2016).

\section{The effect of perceived behavioral control on smoking}

Perceived behavioral control has a significant influence on smoking behavior in adolescents. Weak perceived behavior control on smoking behavior was 2.33 units lower than those who have strong perceived behavioral control. An adolescent felt that smoking was something that was natural and pleasant, not detrimental so they tend to try cigarettes because they felt capable so that the individual's intention to smoke became strong and formed smoking behavior in adolescents.

Behavioral control was the control perception of behavior. Perceived behavioral control has motivational implications for intention, thus producing smoking behavior (Hanson, 2018). Adolescents who have a weak perceived behavioral control would assume that smoking was a natural thing to do and would ultimately strengthen the intention to try smoking so that it would shape the behavior.

\section{The effect of school on smoking behavior among adolescents}

Schools have a significant influence on smoking behavior in adolescents. The results showed that there was a school contextual influence on smoking behavior by 25.14\%. Adolescents spent years in school as members of a small society where there were several tasks to complete and there were rules that limit behavior, feelings and attitudes. Even though they already have clear knowledge and schools that have set rules regarding smoking behavior. In this study, the researchers chose schools based on schools that implement the no-smoking area policy completely and schools that have not fully implemented the nonsmoking area.

School was a very important place to reduce the prevalence of smoking among adolescents/students (Noe et al., 2019). In a school environment, an individual met with many friends from various cultures and different behavior in each individual. Schools with no-smoking policies were well implemented, the ratio of adolescents to smoking was lower than schools without a no-smoking area policy. School linkages and knowledge of public policy were school-level protective factors that restricted adolescents to smoke.

\footnotetext{
AUTHOR CONTRIBUTIONS

$\overline{\text { Shilfia Ulfa Islami as the main researcher }}$ has roles to carry out study, conduct study interventions, formulation of study articles, and data processing. Hanung Prasetya played a role in the formulation of the method in this study. Bhisma Murti played a role in the formulation of research methods and discussion of study results.
} 
Journal of Health Promotion and Behavior (2019), 4(3): 212-223

https://doi.org/10.26911/thejhpb.2019.04.03.06

FUNDING AND SPONSORSHIP

The source of funds in this study used personal funds from the main researcher.

\section{ACKNOWLEDGEMENT}

Acknowledgments were conveyed by author to the Principals of Middle and High Schools in Dumai, Riau, which allowed this study to be carried out.

\section{REFERENCE}

Aho H, Koivisto A, Paavilainen E (2017). Parental involvement and adolescent smoking in vocational setting in Finland. Health Promot Int. 1-12 https://doi.org/10.1093/heapro/dao27.

Alsayyari A, Albuhairan F (2018). Relationship of media exposure to substance use among adolescents in Saudi Arabia: Results from a national study. Drug and Alcohol Dependence. 191: 17418ohttps://doi.org/10.1016/j.drug alcdep.28.01.025.

Aura A, Laatikainen T, Isoaho H, Lazutkina G, Tossavainen K (2016). Adolescents' attitudes on smoking are related to experimentation with smoking, daily smoking and best friends' smoking in two karelias in Finland and in Russia. Int J Behav Med, 23(6): 679-685. https://doi.org/10.1007/s12529-01695667

Bacopoulou F, Vasilaki F, Tsitsimpikou C, Tsatsakis A, Tsarouhas K, Spandidos D, Choursalas A (2018). Health risk behaviors among high school and university adolescent students. Exp Ther Med: 3433-3438. https://doi.org/10.3892/etm.2018.6612

Bendaou B, Zarrouq B, El KK, Lyoussi B, Benjelloun MC, Nejjari C, El Rhazi K (2018). Risk factors and prevalence of use of different tobacco products among school adolescents in the north central region of Morocco: A cross- sectional study. (PAMJ) 30: 1-7. https://doi.org/10.11604/pamj.2018.30. 73.10896

Bigwanto M, Mongkolcharti A, Peltzer K, Laosee O (2015). Determinants of cigarette smoking among school adolescents on the island of Java, Indonesia. (IJAMH), o(o): 1-8. https://doi.org/10.1515/ijamh20150036

Bobo FT, Thanasekaran P, Joice AJR, Yadecha B, Alebel A (2018). Susceptibility to cigarette smoking and associated factors among high school students in western Ethiopia. BMC Research Notes, 11(1):1-5. https://doi.org/10.1186/s131040183734-6

Bruine MD, Giletta M, Denissen JJA, Sijtsema JJ, Oldehinkel AJ (2019). Psychoneuroendocrinology a healthy peer status: Peer preference, not popularity, predicts lower systemic inflammation in adolescence. Psycho neuroendocrinology,109:104402.https://do i.org/10.1016/j.psyneuen.2019.104402.

Cole AG, Aleyan S, Qian W, Leatherdale S $T$ (2019). Assessing the strength of secondary school tobacco policies of schools in the COMPASS study and the association to student smoking behaviours. Can J Public Health, 110(2): 236-243. https://doi.org/10.17269/s41997-019-00178-4

Colombo S, Golzio LE, Bianchi G (2019). The evolution of health, safety and environment-related competencies in Italy: From HSE technicians, to HSE professionals and, eventually, to HSE managers. Safety Science, 118 :724739.https://doi.org/10.1016/j.ssci.2019. 06.002

Cousson-gélie F, Lareyre O, Margueritte M, Paillart J, Huteau M, Djoufelkit K, Stoebner A (2018). Preventing tobacco in vocational high schools: study 
protocol for a randomized controlled trial of $\mathrm{P}_{2} \mathrm{P}$, a peer to peer and theory planned behavior-based program. BMC Public Health 18(1): 494 doi: org/10.1186/s12889-018-0185226y

Cui Y, Forget EL, Zhu Y, Torabi M, Oguzoglu U (2019). The effects of cigarette price and the amount of pocket money on youth smoking initiation and intensity in Canada. Can J Public Health, 110(1): 93102. https://doi.org/10.17269/s41997018-0123-9

Er V, Campbell R, Hickman M, Bonell C, Moore L, White $J$ (2019). The relative importance of perceived substance misuse use by different peers on smoking, alcohol and illicit drug use in adolescence. Drug and Alcohol Dependence, 204: 107464. https://doi.org/10.1016/j.drugalcdep.2019.04.035 .

Hanson MJS (2018). Attitudes and perceptions about cigarette smoking among nonsmoking high school students. $\mathrm{J}$ Am Acad Nurse Prac 30(2018): 6063. doi:10.1097/jxx.00000000005

Mak HW (2018). Parental belief and adolescent smoking and drinking behaviors: A propensity score matching study. Addictive Behaviors Reports, S2352- 8532(17): 30132-3 doi: 10.1016/j.ab.https://doi.org/10.1016/j.abre p.2018.04.003

Moor I, Kuipers MAG, Lorant V, Pförtner T, Kinnunen JM, Rathmann K, Richter $M$ (2019). Inequalities in adolescent self-rated health and smoking in Europe: comparing different indicators of socioeconomic status Epidemiol Community Health 73: 963970. https://doi.org/10.1136/jech2018-211794.

Noe M, Aung H, Yamamoto E, Ko MH, Khaing M, Reyer JA, Hamajima N (2019). Knowledge, attitude, and usage pattern of tobacco among high school students in Nay Pyi Taw, Myanmar. J. Med. Sci. 81:65-79. https://doi.org/10.18999/nagjms.81.1 .65 .

Nurmansyah MI, Umniyatun Y, Jannah M, Syiroj AT, Hidayat DN (2019). Knowledge, attitude and practice of cigarette smoking among senior secondary school students in Depok, Indonesia. (IJAMH): 1-9. https://doi.org/10.1515/ijamh-20180124

Rattay P, Elena VDL, Elvira M, Felichter R, Heike H, Cornelia L, Thomas L (2018). Health and health risk behaviour of adolescents-Differences according to family structure. Results of the German KiGGS cohort study. PLoS ONE, 13(3): 1-19. https://doi.org/10.1371/journal.pone0192968\%o Ahttp://europepmc.org/search?query Pandayu A, Murti B, Pawito (2017). Effect of personal factors, family support, pocket money, and peer group, on smoking behavior in adolescents in Surakarta, Central Java. J Health Promot Behav. 02(02):98-111. https://doi.org/10.26911/thejhpb.2017.02.0201.

Purnaningrum WD, Joebagio H, Murti B (2017). Association between cigarette advertisement, peer group, parental education, family income, and pocket money with smoking behavior among adolescents in Karanganyar District, Central Java. J Health Promot Behav, 02(02):148158.https://doi.org/10.26 911/thejhpb2017.02.02.05

Ra JS, Jung MS (2018). School-related factors affecting smoking intention among Korean middle school students. APPL NURS RES, 39: 34-40. https://doi.org/10.1016/j.apnr.2017.1 0.007 .

Soesyasmoro R A, Demartoto A, Adriani RB 
(2017). Effect of knowledge, peer group, family, cigarette price, stipend, access to cigarette, and attitude, on smoking behavior. J Health Promot Behav 01(03): 201210.https://doi.org/10.26911/thejhpb.2016.01.0307

Steeger CM, Epstein M, Hill K G, Kristmanvalente AN, Bailey JA, Olivia J, Kosterman R (2019). Time-varying effects of family smoking and family management on adolescent daily smoking: The moderating roles of behavioral disinhibition and anxiety. Drug and Alcohol Dependence. 204: 107572. https://doi.org/10.1016/j.drugalcdep. 2019.107572

Sudo A, Kuroda Y (2017). Media exposure, interactive health literacy, and adolescents' susceptibility to future smoking. (IJAMH), 29(2) :1-11 https://doi.org/10.1515/ijamh-2015-0052

Sulaeman ES (2016). PLearning models and theories of health behavior Concepts and Applications. Surakarta:
UNS Press.

Vitória P, Pereira SE, Muinos G, Vries HD, Luísa M (2020). Addictive behaviors parents modelling, peer influence and peer selection impact on adolescent smoking behavior: A longitudinal study in two age cohorts. Addictive Behaviors . Public Health 151:169176https://doi.org/10.1016/j.addbeh.2019.1061

Wu Y, Fan H, Guo Z, Wei L (2019). Factors associated with smoking intentions among Chinese College Students. (AJMH). 13(1):1-8. https://doi.org/10.1177/1557988318818285

Xu X, Chen C, Abdullah AS, Liu L, Sharma M, Li Y, Zhao Y (2016). Smoking related attitudes, motives, and behaviors of male secondary school students in an urban setting of China. Springer Plus, 5(1): 1-9. https://doi.org/10.1186/s40064-016-3694-z. 